\title{
CARACTERIZAÇÃo DE AMOSTRAS DO VÍRUS RÁBICO ISOLADAS DE ANIMAIS DOMÉSTICOS ORIUNDOS DE ÁREAS ENDÊMICAS DO BRASIL
}

\author{
BIOLOGIC AND IMMUNOLOGIC CHARACTERIZATION OF RABIES VIRUS ISOLATES \\ OF DOMESTIC ANIMALS FROM RABIES ENDEMIC AREAS OF BRAZIL
}

Paulo Roberto de OLIVEIRA'; Fumio Honma ITO²; José De Angelis CÔRTES ${ }^{3}$ Silvio Arruda VASCONCELLOS ; Maria da Conceição Aparecida Macedo SOUZA ${ }^{4}$

\begin{abstract}
RESUMO
Trinta e cinco amostras do vírus da raiva, isoladas de material cerebral de animais domésticos procedentes de áreas endêmicas da doença no Brasil, foram estudadas objetivando determinar seu perfil biológico e sua identidade imunológica com a amostra clássica desse virus. Os resultados ofereceram valores, induzidos pela inoculação intracerebral em camundongos, indistintos dos padrões existentes para a amostra clássica, com os seguintes resultados: período de incubação médio de 10,2 dias com extremos, nos valores individuais, mínimo de 4 dias e máximo de 23 dias; período clínico médio da doença de 3,3 dias com extremos, nos valores individuais, mínimo de 1 dia e máximo de 5 dias; patogenicidade global de $96,5 \%$ (adoecendo 332 dos 344 camundongos inoculados em todos os grupos) com extremos mínimo de $66,7 \%$ e máximo de $100 \%$, e manifestações características da raiva. Todas as amostras estudadas reagiram especificamente à prova de imunofluorescência direta aplicada à raiva e apresentaram identidade imunológica com a estirpe clássica do vírus rábico, Sorotipo I, revelada pela prova de soroneutralização em camundongos.
\end{abstract}

UNITERMOS: Zoonoses; Raiva; Vírus da raiva; Antígenos; Imunofluorescência

\section{INTRODUÇÃO}

Desde os primórdios da história do homem, a raiva tem constituído grave obstáculo à qualidade de vida não apenas em razão de perdas econômicas que imprime à produção agropecuária de vários países, mas também pela insegurança que provoca em decorrência da apreensão e medo revelados por todos os indivíduos expostos ao risco de infecção, especialmente nos casos de mordida de um animal raivoso, assumindo, portanto, um papel de destaque entre as zoonoses (ACHA; SZYFRES', 1986).

A vacinação em massa assume papel importante no controle desta doença. Em que pese a qualidade das vacinas antirábicas disponíveis na atualidade, a raiva continua acarretando sérios problemas na pecuária bovina nas áreas onde ela ocorre na forma endêmica, acometendo mesmo animais vacinados (WIKTOR; KOPROWSKI ${ }^{21}$, 1980; LARGHI; DIAZ ${ }^{12}$, 1985), o que vem despertando a preocupação de pesquisadores e profissionais de campo. Tais "falhas de vacinação" têm sido atribuídas a numerosos fatores, entre os quais, a imunodeficiência dos animais (LARGHI; DIAZ ${ }^{12}$, 1985), a

- Professor Titular - Universidade Federal de Uberlândia - MG

- Professor Associado - Faculdade de Medicina Veterinária e Zootecnia da USP-SP

3 - Professor Titular - Faculdade de Medicina Veterinária e Zootecnia da USP-SP

4 - Pós-graduando - Faculdade de Medicina Veterinária e Zootecnia da USP-SP curta duração da imunidade conferida pelas vacinas (WIKTOR; KOPROWSKI ${ }^{21}$, 1980), particularmente em animais primo vacinados; as condições inadequadas de conservação e manuseio das vacinas (ROLLIN et al. ${ }^{16}, 1983$ / 4; LARGHI; DIAZ $\left.{ }^{12}, 1985\right)$. Em adição a esses fatos, alia-se a possibilidade da existência de sorotipos de vírus "relacionados"(BOURHY et al. $\left.{ }^{4}, 1990\right)$ ou mesmo de variantes antigênicas do vírus da raiva, contra os quais a imunidade induzida pela vacina elaborada com amostra da estirpe clássica do agente seria insuficiente para deter a doença (WIKTOR; KOPROWSKI ${ }^{21}$, 1980).

WIKTOR et al. ${ }^{20}(1973)$ demonstraram que a glicoproteína do envelope do vírus rábico era responsável pela indução da formação de anticorpos vírus-neutralizantes e subseqüente proteção dos animais contra o vírus padrão de desafio CVS.

SCHNEIDER et al. ${ }^{17}$ (1973) propuseram método de classificação dos rhabdovírus através da especificidade das reações de neutralização induzidas pelo envelope, que 
OLIVEIRA, R.P.; ITO, F.H.; CÔRTES, J.A.; VASCONCELLOS, S.A.; SOUZA, M.C.A.M. Caracterização de amostras do virus rábico isoladas de animais domésticos oriundos de áreas endêmicas do Brasil. Braz. J. vet. Res. anim. Sci., São Paulo, v.32, n.2, p.89-95, 1995.

determinariam o sorotipo do vírus, e da ribonucleoproteína responsável pelas reações de fixação de complemento, de precipitação em gel de ágar e de anticorpos fluorescentes, que, segundo os autores, seria um antígeno grupo-específico comum a todos os vírus rábicos. Chamaram ainda de variantes os membros do mesmo grupo que apresentaram diferenças biológicas ou antigênicas de menor relevância.

COX et al. ${ }^{5}$ (1977) verificaram ser a glicoproteína do vírus a única proteína estrutural capaz de induzir a formação de anticorpos neutralizantes e conseqüente proteção.

GERMANO et al. ${ }^{6}$ (1988), estudando comparativamente amostras do vírus rábico, sugeriram a necessidade de pesquisas adicionais que esclareçam sobre a possibilidade da existência de estirpes naturais do vírus rábico antigenicamente distintas, oriundas de uma mesma espécie animal, e que apresentem perfil biológico semelhante quando inoculadas experimentalmente em um mesmo sistema.

GERMANO et al. ${ }^{7}$ (1990) determinaram, com o uso de anticorpos monoclonais antinucleocápsides, o perfil antigênico de 13 amostras do vírus rábico, identificando 5 variantes no Nordeste e 2 no Sudeste do Brasil, e associando, ainda, as variações antigênicas a possiveis fracassos na vacinação antirábica.

MIYAMOTO; MATSUMOTO ${ }^{13}$ (1967) verificaram em camundongos infectados com vírus de "rua" excitação de 8 a 10 dias após a inoculação e paralisia típica no dia seguinte à manifestação dos primeiros sinais da doença, enquanto os animais inoculados com a amostra fixa apresentaram paralisia sem excitação, 5 dias após a inoculação.

NILSSON et al. ${ }^{14}$ (1968) encontraram um período médio de incubação de 8,18 dias com extremos de 4 e 19 dias, e a maioria dos camundongos inoculados desenvolveu a doença entre o $6^{\circ}$ e o $10^{\circ}$ dia após a inoculação com uma duração média do período clínico de 2,81 dias, sendo 9 dias o mais longo e 1 dia o menor observado. Os autores afirmaram que variações nas amostras dos vírus estudados e a quantidade de vírus inoculados poderiam afetar o período de incubação da doença em camundongos.

KOPROWSKI ${ }^{11}$ (1975) descreveu os seguintes sintomas observados em camundongos inoculados com o vírus da raiva: pêlo eriçado, tremores quando o animal é levantado pela cauda, incoordenação nas patas posteriores, paralisias e prostração quando próximos da morte. Afirmou que o vírus rábico dificilmente produz manifestações clínicas em camundongos antes de 5 dias, contados a partir da inoculação intracerebral.
BOTROS; $\mathrm{MOCH}^{3}$ (1976), pesquisando as propriedades biológicas e antigênicas de 4 amostras do vírus rábico diagnosticadas pelo exame de imunofluorescência, encontraram o curso da doença variando de 2 a 7 dias. Em relação ao período de incubação, verificaram a existência de um quadro agudo com duração de 3 a 5 dias e outro mais lento de 6 a 10 dias, quando a inoculação era realizada em camundongos.

ATANASIU $^{2}$ (1975), referindo-se à susceptibilidade do camundongo ao vírus rábico, aponta um período de incubação da ordem de 9 a 12 dias após a inoculação intracerebral com vírus de "rua", podendo haver variações desde 7 a 20 dias, e um periodo de doença clínica com duração de 1 a 3 dias.

SWOVELAND; JOHNSON ${ }^{18}$ (1983) defenderam a utilização da prova de anticorpos fluorescentes e da inoculação em camundongos para o diagnóstico da raiva, e observaram um período de 6 a 10 dias de variação para a incubação da doença naquela espécie, quando da inoculação do vírus pela via intracerebral.

KAPLAN et al. ${ }^{10}$ (1986) verificaram que anticorpos desenvolvidos contra a ribonucleoproteína pura do vírus rábico não possuem atividade neutralizante, mas em conjugados imunofluorescentes coram inclusões intracitoplasmáticas (corpúsculos de Negri) reagindo de forma cruzada com a ribonucleoproteína do vírus do subgrupo rábico.

O presente trabalho teve como objetivo estudar a caracterização de amostras de vírus da raiva, isoladas de animais procedentes de algumas áreas endêmicas da doença no Brasil, comparandoas, particularmente no que concerneà identidade imunológica, com a estirpe clássica desse vírus, e caracterizar o perfil biológico das amostras estudadas inoculadas em camundongos, verificando sintomas, patogenicidade, período de incubação e período de duração da doença, comparando-o com as características já estabelecidas para o vírus rábico clássico.

\section{MATERIAL E MÉTODO}

Foram utilizadas 35 amostras de campo do vírus, diagnosticadas como sendo da raiva, recém-colhidas, tomadas de diferentes espécies animais (cães, bovinos, eqüinos e suínos), procedentes de áreas endêmicas da doença. Dessas amostras, 20 foram originárias do Estado de São Paulo, 2 do Estado de Minas Gerais, 4 do Estado do Mato Grosso do Sul e 9 do Estado de Goiás.

Após a reativação das amostras em laboratório, por inoculação intracerebral em camundongos, KOPROWSKJ ${ }^{11}$ (1975) observou as peculiaridades da relação hospedeiro-parasita 
OLIVEIRA, R.P.; ITO, F. H.; CÔRTES, J.A.; VASCONCELLOS, S.A.; SOUZA, M.C.A.M. Caracterização de amostras do vírus rábico isoladas de animais domésticos oriundos de áreas endêmicas do Brasil. Braz. J. vet. Res. anim. Sci., São Paulo, v.32, n.2, p.89-95, 1995.

entre as amostras estudadas e os camundongos inoculados, particularmente no tocante ao período clínico e natureza dos sinais apresentados pelos animais, bem como as características dos corpúsculos de Negri desenvolvidos, especialmente com vistas à sua morfologia e natureza da fluorescência, verificada por meio da prova de imunofluorescência direta (IFD), realizada de conformidade com GOLDWASSER; KISSLING ${ }^{8}$ (1958).

Todas as amostras foram submetidas à prova de soro-vírusneutralização em camundongos de acordo com os princípios recomendados por JOHNSON ${ }^{9}$ (1975), quando foram confrontadas com o soro padrão anti-rábico hiperimune, gentilmente cedido pelo Instituto Butantan.

Os animais inoculados foram observados diariamente, durante 28 dias, registrando-se, para fins de interpretação das provas, as mortes ocorridas a partir do $4^{\circ}$ dia, quando acompanhadas dos sinais clássicos da raiva. $O$ cálculo dos títulos dos vírus e as correspondentes DL50\% foram realizados segundo os princípios estabelecidos por REED; $\operatorname{MUENCH}^{15}(1938)$.

\section{RESULTADOS E DISCUSSÃO}

Dos 350 camundongos utilizados na prova de inoculação intracerebral para caracterização do perfil biológico das amostras de vírus estudadas, 6 morreram de acidente de manejo, durante a operação de inoculação, e 12 não adoeceram. No tocante às manifestações clínicas, o quadro observado incluiu, em todos os casos, excitação, sensibilidade ao ar (aerofobia) quando provocados, agressividade, emagrecimento rápido, paralisia ascendente e morte, o que está em consonância com os achados descritos pelos autores que estudaram o vírus da raiva (MIYAMOTO; MATSUMOTO ${ }^{13}$, 1967; NILSSON et al. ${ }^{14}$, 1968; ATANASIU $^{2}, 1975$; KOPROWSKI $\left.{ }^{11}, 1975\right)$.

A Tab. 1 revela-nos que, no conjunto de camundongos infectados com todas as amostras, o período de incubação oscilou entre 4 e 23 dias, e que o aparecimento dos sinais nos 35 grupos apresentou uma concentração acentuada de casos entre o $6^{\circ}$ e o $14^{\circ}$ dia $(92,2 \%)$, sendo $55 \%$ destes entre o $8^{\circ}$ e $11^{\circ}$ dia após a infecção. O período da incubação médio obtido de 10,2 dias não é diferente daquele verificado por outros autores como MIYAMOTO; MATSUMOTO ${ }^{13}$ (1967), NILSSON et al. ${ }^{14}(1968)$ e ATANASIU ${ }^{2}$ (1975). No tocante à freqüência de desenvolvimento de sinais, NILSSON et al. ${ }^{14}$ (1968) e SWOVELAND; JOHNSON ${ }^{18}$ (1983) registraram suas observações entre o $6^{\mathrm{e}}$ e o $10^{\mathrm{Q}}$ dia após a inoculação. Essas pequenas diferenças se explicariam pela dose de vírus utilizada (NILSSON et al. ${ }^{14}, 1968$ ), bem como pela adaptação da amostra estudada à espécie empregada como sistema biológico, de acordo com GERMANO et al. ${ }^{6}$ (1988).

\section{TABELA 1}

Números de camundongos com início dos sinais, segundo os diferentes momentos do período de incubação expresso em dias pós-inoculação e o correspondente valor percentual. São Paulo, 1992.

DIAS PÓS-INOCULAÇ̃̃O № DE ANIMAIS PERCENTAGEM

\begin{tabular}{rrrr}
\hline 4 & 1 & 0,3 \\
5 & 4 & 1,2 \\
6 & 22 & 6,6 \\
7 & 32 & 9,6 \\
8 & 58 & 17,4 \\
9 & 44 & 13,2 \\
10 & 32 & 9,6 \\
11 & 49 & 14,8 \\
12 & 15 & 4,5 \\
13 & 26 & 7,8 \\
14 & 29 & 8,7 \\
15 & 6 & 1,8 \\
16 & 2 & 0,6 \\
17 & 3 & 0,9 \\
18 & 2 & 0,6 \\
19 & 5 & 1,5 \\
20 & 0 & 0 \\
21 & 0 & 0 \\
& 22 & 1 & 0,3 \\
& & 0,3 \\
TOTAL & 1 & 0 \\
\hline
\end{tabular}

Relativamente ao curso da doença, verificou-se uma duração clínica média de 3,3 dias, sendo os períodos mínimo e máximo de 1 e 8 dias respectivamente, e que $91,2 \%$ dos animais vieram a sucumbir entre o $1^{9}$ e o $5^{\circ}$ dia (Tab. 2). Tais achados estão em consonância com os de BOTROS; $\mathrm{MOCH}^{3}$ (1976), que apontaram 2 e 7 dias como valores extremos, e NILSSON et al. ${ }^{14}$ (1968), cujos extremos oscilaram entre 1 e 9 dias, para um período médio de 2,8 dias. São igualmente concordantes os valores médios de duração da doença entre 1 e 3 dias apontados por ATANASIU² (1975). Todos os autores enfatizam o caráter agudo e letal da doença.

A Tab. 3 revela valores relativos à patogenicidade das amostras estudadas. No que diz respeito à patogenicidade, os valores oscilaram entre 66,7 e $100 \%$, com uma média global de $96,5 \%$, de forma semelhante ao encontrado por WEBSTER; DAWSON ${ }^{19}$ (1935).

Verificou-se através da Tab. 4 uma estreita afinidade sorológica, detectada pela reação de imunofluorescência direta, entre as amostras de vírus estudadas e os anticorpos 
OLIVEIRA, R.P.; ITO, F.H.; CÔRTES, J.A.; VASCONCELLOS, S.A.; SOUZA, M.C.A.M. Caracterização de amostras do vírus rábico isoladas de animais domésticos oriundos de áreas endêmicas do Brasil. Braz. J. vet. Res. anim. Sci., São Paulo, v.32, n.2, p.89-95, 1995.

\section{TABELA 2}

Duração clínica da raiva em camundongos inoculados pela via intracerebral com material de campo oriundo de áreas endêmicas da doença, segundo o número de animais e o período de sobrevivência destes em dias. São Paulo, 1992.

\begin{tabular}{ccc}
\hline $\begin{array}{c}\text { DURAC̆̃ CLÍNICA } \\
\text { (DIAS) }\end{array}$ & No DE ANIMAIS & $\begin{array}{c}\text { PERCENTUAL } \\
(\%)\end{array}$ \\
\hline 1 & 50 & 15.0 \\
2 & 63 & 19.0 \\
3 & 94 & 28.3 \\
4 & 55 & 16.6 \\
5 & 41 & 12.3 \\
6 & 21 & 6.3 \\
7 & 5 & 1.5 \\
8 & 3 & 0.9 \\
\hline TOTAL & 332 & 100 \\
\hline
\end{tabular}

marcados (conjugados), elaborados a partir da amostra clássica (PV) do vírus da raiva. Como essa reação está associada a anticorpos "grupo-específico", obtidos a partir da ribonucleoproteína do vírus, que reagem de forma cruzada com outros vírus do subgrupo da raiva (SCHNEIDER et al. ${ }^{17}$, 1973; WIKTOR et al. ${ }^{20}$, 1973; KAPLAN et al. ${ }^{10}$, 1986), a presença de resultados positivos em todos os materiais examinados constitui apenas um elemento adicional na caracterização do perfil das amostras estudadas. Ainda através da Tab. 4, no tocante à soroneutralização, os resultados obtidos mostraram que o soro hiperimune produzido com a estirpe clássica do vírus rábico (amostra PV) foi capaz de proteger a totalidade dos animais contra o desafio virulento, com pelo menos $250 \mathrm{DL}_{50}$ das diferentes amostras de vírus isoladas dos materiais de campo estudados. JOHNSON ${ }^{9}$ (1975) indica que acima de $100 \mathrm{DL}_{50}$ neutralizadas a identidade do vírus é estabelecida. Tratando-se de uma prova associada a um anticorpo "tipo-específico", obtido a partir da glicoproteína do vírus (WIKTOR et al. ${ }^{20}$, 1973; COX et al. ${ }^{5}$, 1977; BOURHY et al. ${ }^{4}, 1990$ ), fica claro o valor discriminativo dessa reação na identificação do vírus rábico, com o que concorda JOHNSON ${ }^{9}$ (1975), que é bastante incisivo ao afirmar que a neutralização de tais vírus por um soro hiperimune anti-rábico, elaborado a partir da estirpe clássica, é indício seguro de homologia imunológica e permite concluir

\section{TABELA 3}

Valores relativos à patogenicidade, pela infecção experimental em camundongos via intracerebral, de amostras de campo do vírus da raiva, segundo sua procedência. São Paulo, 1992.

\begin{tabular}{|c|c|c|c|}
\hline \multirow[t]{2}{*}{ AMOSTRA } & PROCEDÊNCIA & \multicolumn{2}{|l|}{ PATOGENICIDADE } \\
\hline & (U.F.) & (DOENTES/INOCULADOS) & $(\%)$ \\
\hline 04 & SP & $10 / 10$ & 100 \\
\hline 06 & SP & $08 / 09$ & 88.9 \\
\hline 07 & $\mathrm{SP}$ & $09 / 10$ & 90 \\
\hline 08 & SP & $10 / 10$ & 100 \\
\hline 09 & SP & $10 / 10$ & 100 \\
\hline 10 & SP & $08 / 10$ & 80 \\
\hline 11 & SP & $08 / 10$ & 80 \\
\hline 12 & SP & $08 / 09$ & 88.9 \\
\hline 13 & SP & $06 / 09$ & 66.7 \\
\hline 14 & $\mathrm{SP}$ & $08 / 09$ & 88.9 \\
\hline 17 & SP & $10 / 10$ & 100 \\
\hline 23 & SP & $10 / 10$ & 100 \\
\hline 24 & SP & $10 / 10$ & 100 \\
\hline 25 & SP & $10 / 10$ & 100 \\
\hline 26 & SP & $10 / 10$ & 100 \\
\hline 27 & SP & $10 / 10$ & 100 \\
\hline 28 & $\mathrm{SP}$ & $10 / 10$ & 100 \\
\hline 29 & $\mathrm{SP}$ & $10 / 10$ & 100 \\
\hline 30 & SP & $10 / 10$ & 100 \\
\hline 31 & SP & $10 / 10$ & 100 \\
\hline 32 & $\mathrm{MG}$ & $10 / 10$ & 100 \\
\hline 33 & $\mathrm{MG}$ & $10 / 10$ & 100 \\
\hline 34 & MS & $10 / 10$ & 100 \\
\hline 35 & MS & $10 / 10$ & 100 \\
\hline 36 & MS & $09 / 09$ & 100 \\
\hline 37 & $\mathrm{MS}$ & $10 / 10$ & 100 \\
\hline 38 & $\mathrm{GO}$ & $09 / 10$ & 90 \\
\hline 39 & GO & $10 / 10$ & 100 \\
\hline 40 & GO & $10 / 10$ & 100 \\
\hline 41 & $\mathrm{GO}$ & $09 / 09$ & 100 \\
\hline 42 & $\mathrm{GO}$ & $10 / 10$ & 100 \\
\hline 43 & GO & $10 / 10$ & 100 \\
\hline 44 & GO & $10 / 10$ & 100 \\
\hline 45 & GO & $10 / 10$ & 100 \\
\hline 46 & GO & $10 / 10$ & 100 \\
\hline TOTAL & & $332 / 344$ & 96.5 \\
\hline
\end{tabular}


OLIVEIRA, R.P.; ITO, F. H.; CÔRTES, J.A.; VASCONCELLOS, S.A.; SOUZA, M.C.A.M. Caracterização de amostras do vírus rábico isoladas de animais domésticos oriundos de áreas endêmicas do Brasil. Braz. J. vet. Res. anim. Sci., São Paulo, v.32, n.2, p.89-95, 1995.

TABELA 4

Valores relativos à identidade imunológica, pela soroneutralização em camundongos, e à identidade sorológica, pela imunofluorescência direta, das amostras estudadas com a estirpe clássica do vírus da raiva, segundo sua procedência. São Paulo, 1992.

\begin{tabular}{|c|c|c|c|c|}
\hline \multirow{3}{*}{\multicolumn{2}{|c|}{$\begin{array}{l}\text { AMOSTRA PROCEDÊNCIA } \\
\text { (U.F.) }\end{array}$}} & \multicolumn{3}{|c|}{ IDENTIDADE } \\
\hline & & \multicolumn{2}{|c|}{ Imunológica } & \multirow[t]{2}{*}{ Sorológica } \\
\hline & & (PROT./ INOC.)* & $\mathrm{DL}_{50}$ & \\
\hline 04 & SP & $08 / 08$ & $>3,0^{* *}$ & $P$ \\
\hline 06 & SP & $10 / 10$ & $>3,0$ & $\mathrm{P}$ \\
\hline 07 & SP & $10 / 10$ & $>3,0$ & $P$ \\
\hline 08 & SP & $10 / 10$ & $>3,0$ & $\mathrm{P}$ \\
\hline 09 & SP & $10 / 10$ & 2,8 & $\mathrm{P}$ \\
\hline 10 & SP & $10 / 10$ & 2,8 & $\mathrm{P}$ \\
\hline 11 & SP & $10 / 10$ & 2,6 & $\mathrm{P}$ \\
\hline 12 & SP & $10 / 10$ & 3,0 & $\mathrm{P}$ \\
\hline 13 & SP & $10 / 10$ & 2,4 & $\mathrm{P}$ \\
\hline 14 & SP & $10 / 10$ & 2,6 & $\mathrm{P}$ \\
\hline 17 & SP & $10 / 10$ & $>3,0$ & $\mathrm{P}$ \\
\hline 23 & SP & $09 / 09$ & $>3,0$ & $P$ \\
\hline 24 & SP & $10 / 10$ & 2,8 & $P$ \\
\hline 25 & SP & $10 / 10$ & $>3,0$ & $\mathrm{P}$ \\
\hline 26 & SP & $10 / 10$ & $>3,0$ & $\mathrm{P}$ \\
\hline 27 & SP & $10 / 10$ & $>3,0$ & $\mathrm{P}$ \\
\hline 28 & SP & $10 / 10$ & $>3,0$ & $\mathrm{P}$ \\
\hline 29 & SP & $09 / 09$ & $>3,0$ & $\mathrm{P}$ \\
\hline 30 & SP & $09 / 09$ & $>3,0$ & $P$ \\
\hline 31 & SP & $10 / 10$ & $>3,0$ & $P$ \\
\hline 32 & MG & $10 / 10$ & $>3,0$ & $\mathrm{P}$ \\
\hline 33 & $\mathrm{MG}$ & $10 / 10$ & $>3,0$ & $\mathrm{P}$ \\
\hline 34 & $\mathrm{MS}$ & $09 / 09$ & $>3,0$ & $\mathrm{P}$ \\
\hline 35 & MS & $10 / 10$ & $>3,0$ & $P$ \\
\hline 36 & MS & $10 / 10$ & $>3,0$ & $P$ \\
\hline 37 & MS & $10 / 10$ & $>3,0$ & $P$ \\
\hline 38 & GO & $09 / 09$ & $>3,0$ & $\mathrm{P}$ \\
\hline 39 & GO & $10 / 10$ & $>3,0$ & $\mathrm{P}$ \\
\hline 40 & GO & $09 / 09$ & $>3,0$ & $\mathrm{P}$ \\
\hline 41 & GO & $08 / 08$ & 2,6 & $\mathrm{P}$ \\
\hline 42 & GO & $10 / 10$ & $>3,0$ & $\mathrm{P}$ \\
\hline 43 & GO & $10 / 10$ & $>3,0$ & $P$ \\
\hline 44 & GO & $10 / 10$ & $>3,0$ & $\mathrm{P}$ \\
\hline 45 & GO & $10 / 10$ & 2,6 & $P$ \\
\hline 46 & GO & $10 / 10$ & $>3,0$ & $\mathrm{P}$ \\
\hline TOTAL & & $340 / 340$ & & $35 / 35$ \\
\hline
\end{tabular}

* Protegidos/Inoculados

** Valor logarítmico do número de $\mathrm{DL}_{50}$ neutralizados tratar-se do mesmo sorotipo.

Esses achados são da mais alta relevância para a epidemiologia da raiva, uma vez que, a despeito da possibilidade da existência de variações antigênicas menores entre as diferentes estirpes do vírus (WIKTOR; KOPROWSKI ${ }^{21}, 1980$ ), inclusive no Brasil (GERMANO et al. ${ }^{7}$, 1990), as amostras do vírus rảbico, objeto do presente estudo, isoladas em áreas endêmicas de raiva no país, revelaram-se imunogenicamente homólogas ả estirpe clássica, a partir da qual são elaboradas as vacinas.

A ocorrência de casos fatais de raiva em áreas endêmicas, mesmo em animais vacinados, segundo LARGHI; DIAZ ${ }^{12}$ (1985), estaria associada mais às múltiplas variáveis de vacinação em si e à qualidade da vacina, que a diferenças imunológicas entre as amostras do vírus rábico. WIKTOR; KOPROWSKI ${ }^{21}$ (1980) apontam como causa importante na falha do tratamento humano pós-exposição o atraso no início de sua administração, e ROLLIN et al. ${ }^{16}$ (1983/4) acrescentam, relativamente a ambas as situações, o abandono injustificado do tratamento humano e a vacinação tardia ou irregular dos animais domésticos.

\section{CONCLUSÕES}

Os resultados obtidos no presente estudo permitem assegurarse as seguintes conclusões:

1. Há uma completa identidade imunológica e sorológica entre a estirpe clássica do vírus da raiva (amostra PV) e as amostras dos vírus utilizadas no presente estudo, obtidas a partir do tecido nervoso de animais acometidos pela raiva em regiões endêmicas dessa doença no Brasil.

2. Resguardadas as limitações de natureza intrínseca das variáveis patogenicidade, período de incubação e período de duração da doença, os resultados obtidos no presente estudo revelaram-se indistintos dos parâmetros de características biológicas disponíveis na atualidade, observados em outros estudos realizados com a amostra clássica do vírus da raiva. 
OLIVEIRA, R.P.; ITO, F.H.; CÔRTES, J.A.; VASCONCELLOS, S.A.; SOUZA, M.C.A.M. Caracterização de amostras do vírus rábico isoladas de animais domésticos oriundos de áreas endêmicas do Brasil. Braz. J. vet. Res. anim. Sci., São Paulo, v.32, n.2, p.89-95, 1995.

\begin{abstract}
SUMMARY
Biologic and immunologic profiles of rabies virus isolates obtained from domestic animals of endemic areas were compared to the CVS rabies virus by means of mice inoculation, serum-neutralization test and by the fluorescent antibody technique (FA). The mean incubation period was 10.2 days, with a range of 4 and 23 days; the disease period was found with a mean period of 3.3 days with a range of 1 and 5 days; the overall value of pathogenicity was $96.5 \%(332 / 344)$ and clinical manifestations all resembled rabies. All rabies virus isolates have reacted specifically to FA test and they all revealed immunologic identity to the standard strain of the CVS virus through the serum-neutralization technique.
\end{abstract}

UNITERMS: Zoonoses; Rabies; Rabies virus; Antigens, Immunofluorescence

\title{
REFERÊNCIAS BIBLIOGRÁFICAS
}

1-ACHA, P.N.; SZFRES, B. Zoonosis y enfermedades transmisibles comunes al hombre e a los animales. 2. ed. Washington, Organización Panamericana de la Salud, 1986.

2-ATANASIU, P. Animal inoculation and the Negri body. In: BAER, G.M., ed.The natural history of rabies. New York, Academic Press, 1975. v.1, p.373-400.

3-BOTROS, B.A.M.; MOCH, R.W. Rabies in Egypt: biological and antigenic properties of four viruses recovered from non classical rabies cases. Bulletin of Animal Health and Production in Africa, v.24, p.34-42, 1976.

4-BOURHY, H.; SUREAU, P.; TORDO, N. From rabies to rabies-related viruses. Veterinary Microbiology, v.23, p.1158, 1990.

5-COX, J.H.; DIETZSCHOLD, B.; SCHNEIDER, L.G. Rabies virus glycoprotein. II. Biological and sorological characterization. Infection and Immunity, v.16, p.754-9, 1977.

6-GERMANO, P.M.L.; MIGUEL, O.; ISHIZUKA, M.M.; SILVA, E.V. Avaliação de três cepas de vírus rábico antigenicamente distintas, em camundongos. I. Estudo dos períodos de observação clínica. Revista de Saúde Pública, São Paulo, v.22, p.375-83, 1988.

7-GERMANO, P.M.L.; SILVA, E.V.; MIGUEL, O.; SUREAU, P. Variantes antigénicas del virus de la rabia aisladas en el nordeste e sudeste del Brasil. Estudio preliminar. Boletín de la Oficina Sanitaria Panamericana, v.108, p.3944, 1990.

8-GOLDWASSER, R.A.; KISSLING, R.E. Fluorescent antibody staining of street and fixed rabies virus antigens. Proceedings of the Society for Experimental Biology and Medicine, New York, v.98, p.219-23, 1958.

9-JOHNSON, H.N. La prueba del índice de neutralización del virus en ratones. In: ORGANIZACIÓN MUNDIAL DE LA SALUD.La rabia: técnicas de laboratorio. 3.ed. Ginebra, 1975. p.98-101. (Série de Monografias, 23)
10-KAPLAN, C.; TURNER, G.S.; WARRELL, D.A. Rabies: the facts. 2.ed. Oxford, Oxford University Press, 1986.

11-KOPROWSKI, H. Prueba de inoculación en el ratón. In: ORGANIZACIÓN MUNDIAL DE LA SALUD. La rabia: técnicas de laboratorio. 3.ed. Ginebra, 1975. p.88-97. (Série de Monografias, 23)

12-LARGHI, O.P.; DIAZ, M.O. Cross protection of mice against different rabies virus isolates. Zentralblate für Bakteriologie, Mikrobiologie und Hygiene. ABt 1. Originale A, v.259, p.268-74, 1985.

13-MIYAMOTO, K.; MATSUMOTO, S. Comparative studies between pathogenesis of street and fixed rabies infection. The Journal of Experimental Medicine, v.125, p.44756, 1967.

14-NILSSON, M.R.; SUGAY, W.; PASQUALIN, O.L. Diagnóstico da raiva, observações sobre o tempo de incubação e a duração da doença em camundongos, no período de 1960 a 1966. Arquivos do Instituto Biológico, São Paulo, v.25, p.1-7, 1968

15-REED, L.J.; MUENCH, H. A simple method of estimating fifty percent end points. American Journal of Hygiene, v.27, p.493-7, 1938.

16-ROLLIN, P.E.; SUREAU, P.; RAKOTONININARANDRIAMBELOMA, P.J.; CONLANGES, P. Caractéristiques antigeniques de souches de rage isolées a Madagascar. Archives de l'Institut Pasteur de Madagascar, v.51, p.105-12, 1983/ 4.

17-SCHNEIDER, L.G.; DIETZSCHOLD, B.; DIERKS, R.E.; MATTHAEUS, W.; ENZMANN, P.J.; STROHMAIER, $\mathrm{K}$. Rabies group-specific ribonucleoprote in antigen and typing of rhabdoviruses.Journal of Virology, v. 11, p.748-55, 1973.

18-SWOVELAND, P.T.; JOHNSON, K.P.Identification of rabies antigen in human and animal tissues. Annals of the New 
OLIVEIRA, R.P.; ITO, F. H.; CÔRTES, J.A.; VASCONCELLOS, S.A.; SOUZA, M.C.A.M. Caracterização de amostras do vírus rábico isoladas de animais domésticos oriundos de áreas endêmicas do Brasil. Braz. J. vet. Res. anim. Sci., São Paulo, v.32, n.2, p.89-95, 1995.

typing of rhabdoviruses. Journal of Virology, v.11, p.74855, 1973.

18-SWOVELAND, P.T.; JOHNSON, K.P. Identification of rabies antigen in human and animal tissues. Annals of the New York Academy of Sciences, v.420, p.185-91, 1983.

19-WEBSTER, L.T.; DAWSON, J.R. Early diagnosis of rabies by mouse inoculation. Measurement of humoral immunity to rabies by mouse protection test. Proceedings of the Society for Experimental Biology and Medicine, v.32, p.570-3, 1935.

20-WIKTOR, T.J.; GYORGY, E.; SCHLUMBERGER, H.D.; SOKOL, F.; KOPROWSKI, H. Antigenic properties of rabies virus components. The Journal of Immunology, v.110, p.269-76, 1973.
21-WIKTOR, T.J.; KOPROWSKI, H. Antigenic variants of rabies virus. The Journal of Experimental Medicine, v.152, p.99-112, 1980.
Recebido para publicação em 04/01/94 Aprovado para publicação em 10/10/94 